\title{
Sensitivity to Ingroup and Outgroup Norms in the Association Between Commonality and Morality
}

\author{
Megan R. Goldring ${ }^{\mathrm{a}}$ \& Larisa Heiphetz ${ }^{\mathrm{b}}$ \\ ${ }^{a}$ Department of Psychology, Columbia University. 1190 Amsterdam Ave., New York, NY \\ 10027, United States. E-mail: m.goldring@columbia.edu. Phone: 818-917-7528. (Corresponding \\ Author) \\ ${ }^{\mathrm{b}}$ Department of Psychology, Columbia University. 1190 Amsterdam Ave., New York, NY \\ 10027, United States. E-mail: lah2201@columbia.edu. Phone: 212-854-1348.
}

Citation: Goldring, M. R., \& Heiphetz, L. (2020). Sensitivity to ingroup and outgroup norms in the association between commonality and morality. Journal of Experimental Social Psychology, 91, 104025. doi: 10.1016/j.jesp.2020.104025

Acknowledgements: The authors wish to thank members of the Social and Moral Cognition Lab for feedback on this work. This project was supported by an APA Graduate Student Research Grant awarded to the first author. The APA was not involved in decisions concerning study design; in the collection, analysis, and interpretation of data; in the writing of the report; and in the decision to submit this article for publication. This work was also supported (in part) by a Visiting Scholar award from the Russell Sage Foundation to the second author. Any opinions expressed are those of the authors alone and should not be construed as representing the opinions of the Foundation. 


\begin{abstract}
Emerging research suggests that people infer that common behaviors are moral and vice versa. The studies presented here investigated the role of group membership in inferences regarding commonality and morality. In Study 1, participants expected a target character to infer that behaviors that were common among their ingroup were particularly moral. However, the extent to which behaviors were common among the target character's outgroup did not influence expectations regarding perceptions of morality. Study 2 reversed this test, finding that participants expected a target character to infer that behaviors considered moral among their ingroup were particularly common, regardless of how moral their outgroup perceived those behaviors to be. While Studies 1-2 relied on fictitious behaviors performed by novel groups, Studies 3-4 generalized these results to health behaviors performed by members of different racial groups. When answering from another person's perspective (Study 3) and from their own perspective (Study 4), participants reported that the more common behaviors were among their ingroup, the more moral those behaviors were. This effect was significantly weaker for perceptions regarding outgroup norms, although outgroup norms did exert some effect in this real-world context. Taken together, these results highlight the complex integration of ingroup and outgroup norms in socio-moral cognition.
\end{abstract}

Keywords: health behaviors, moral cognition, norms, racial groups 


\section{Sensitivity to Ingroup and Outgroup Norms in the Association Between Commonality and Morality}

Enlightenment thinker David Hume noted that people conflate 'what is common' and 'what is moral' (Hume, 1738/2003). Nearly 300 years later, a rich body of empirical evidence substantiates Hume's observation. When told that a behavior is common, people infer that it is moral (Lindström, Jangard, Selbing, \& Olsson, 2018), and when told that a behavior is moral, people infer that it is common (Eriksson, Strimling, \& Coultas, 2015). Perceptions of commonality and morality are inextricably linked (Bear \& Knobe, 2017).

Of course, what is considered common and what is considered moral depends heavily on the social group to which a person belongs (Costa, Terraciano, \& McCrae, 2001; Heinrichs et al., 2006; Leach, Bilali, \& Pagliaro, 2015; Mu, Kitayama, Han, \& Gelfand, 2015; Roos, Gelfand, Nau, \& Lun, 2015; Suh, Diener, Oishi, \& Triandis 1998). For example, 7- to 9-year-old children and adults only say it is okay for a fictitious group, Glerks, to drink juice out of a bowl when other Glerks drink juice out of a bowl, but not when Hibbles do (Roberts, Gelman, \& Ho, 2019). Similarly, adults only think strangers from a faraway land would say that a behavior is common when those people believe that the behavior is moral (Eriksson, Strimling, \& Coultas, 2015). Some existing research on the association between commonality and morality therefore acknowledges that normative reasoning is inherently group-based, showing that people (Abrams, Rutland \& Cameron, 2003; Nesdale \& Lawson, 2011) and their behaviors (Rhodes \& Chalik, 2013; Roberts, Gelman, \& Ho, 2018; Roberts, Guo, Ho \& Gelman, 2017; Roberts, Ho, \& Gelman, 2017; Roberts, Ho, \& Gelman, 2019) are devalued insofar as they violate the norms of their own group. 
Interestingly, this prior work has focused on the effects of commonality and morality for behaviors that are perfectly differentiated by group status. In these studies, behaviors are depicted as common either among the ingroup or the outgroup, but never both (i.e. Abrams, Rutland \& Cameron, 2003; Nesdale \& Lawson, 2011; Rhodes \& Chalik, 2013; Roberts, Gelman, \& Ho, 2018; Roberts, Guo, Ho \& Gelman, 2017; Roberts, Ho, \& Gelman, 2017; Roberts, Ho, \& Gelman, 2019). Similarly, some work has depicted behaviors as moral among a person's ingroup without providing information about outgroup norms (Eriksson et. al, 2015).

Together, this research highlights that ingroup norms govern socio-moral cognition. However, behaviors are rarely differentiated so strictly by group membership in the world outside the lab. Instead, behaviors can be common or uncommon among both ingroup and outgroup members. For example, getting the flu shot is most common among Asian-Americans, although people from other racial groups certainty also get the flu shot (U.S. Center for Disease Control, 2016). This raises the question: Would Asian-Americans consider getting the flu shot to be especially moral if they perceived that it was relatively common among both AsianAmericans and outgroup members? Or would Asian-Americans perceive the flu shot to be more moral if they knew that it was common among their ingroup but less common among their outgroup? In other words, if ingroup norms are held constant, to what extent do people incorporate outgroup norms when reasoning from commonality to morality and vice versa? The answers to these questions depend on the extent to which people are sensitive to outgroup norms. Interestingly, different psychological theories predict different outcomes.

\section{Psychological Theories in Support of Outgroup Sensitivity}

One possibility is that people are sensitive to outgroup norms such that the link between commonality and morality depends on outgroup norms as well as ingroup norms. This 
hypothesis stems from work on the 'common is moral' heuristic and on intergroup bias, although these two literatures differ in exactly how they expect outgroup norms to matter.

Work on the 'common is moral' heuristic leverages methods from cognitive psychology to show that people infer morality from commonality (the common is moral hypothesis). In speeded reaction-time tasks, perceptions of commonality predict perceptions of morality so quickly that those inferences are presumed to take place below the level of conscious awareness (Lindström et al., 2018). Generalizing this finding across groups implies that people may perceive behaviors to be the most moral when the largest number of individuals engage in those behaviors, which would occur when people from multiple groups enact them. Indeed, certain behaviors that are prevalent across cultures are considered to be universally moral, such as avoiding purposeful harm to others (Haidt, 2013). By the same token, people may presume that behaviors that multiple groups perceive as moral are particularly common. In line with this notion, people believe others are fundamentally moral 'deep down inside' (De Freitas \& Cikara, 2018; Heiphetz, Strohminger, Gelman, \& Young, 2018; Newman, Bloom, \& Knobe, 2014). In line with this work, people may perceive even outgroup members as morally good and expect them to engage in moral behaviors (De Freitas \& Cikara, 2018). Accordingly, perceiving that both ingroup and outgroup members view a behavior as moral might increase the degree to which it is perceived as common.

Research from the intergroup cognition literature also supports the hypothesis that people are sensitive to outgroup information in their norm-based reasoning, but in a way that further differentiates, rather than unites, judgments for behaviors across groups (the group differentiation hypothesis). Social Identity Theory posits that people are motivated to distinguish between their own group and other groups as a way to develop and maintain a positive image of 
themselves and their ingroup (Tajfel, Turner, Austin, \& Worchel, 1979). As such, people perceive ingroup members as more warm, competent, and moral than outgroup members (Abele et al., 2016; Brambilla \& Leach, 2014; Fiske, 2018). From this perspective, a behavior that is common among one's ingroup would only be considered moral if the outgroup does not engage in that behavior. This perception would allow people to leverage normative differences between ingroups and outgroups in order to perceive their own group as most moral. Such a finding would align with the fact that people act more in line with ingroup norms when they are primed to think of the outgroup (Hall \& Crisp, 2008). People might therefore perceive behaviors that are considered moral among their ingroup but not their outgroup as the most common.

\section{Psychological Theory Opposed to Outgroup Sensitivity}

An alternative possibility is that inferences about commonality based on morality, and inferences about morality based on commonality, are not sensitive to outgroup norms (i.e., the perceived outgroup irrelevance hypothesis). People are highly attuned to others' attitudes, but such sensitivity may pertain mostly to ingroup opinions (Hysenbelli, Rubaltelli, \& Rumiati, 2013). Thus, information about outgroup norms may not play a strong role in participants' inferences. In a direct test of this hypothesis, Smith and Louis (2008) found a significant interaction between moral and common norms that did not depend on the outgroup. In their Study 2, participants were more likely to adopt a behavior when an ingroup member engaged in it, regardless of whether outgroup members performed that behavior. However, this study only examined the association between commonality and morality for attitudes and behaviors that had nothing to do with the outgroup. Specifically, this study tested whether students were more likely to support and sign a petition about their own school when other students in their school signed it and whether this effect was moderated by the number of signatures obtained from students at 
another school. In such a context, outgroup norms may have seemed irrelevant because the effects of the passed petition had no bearing on students in another school. In many real-world contexts, however, perceptions of morality and commonality do have implications for outgroup members.

The current studies investigated whether people incorporate outgroup information for behaviors and attitudes that are relevant to members of multiple groups within a society. We examined whether behaviors that were common among both the ingroup and the outgroup are perceived as the most moral (in line with the common is moral hypothesis) or whether behaviors that are common among the ingroup but not the outgroup are perceived as most moral (in line with the group differentiation hypothesis). We simultaneously probe whether behaviors that are common among the ingroup are perceived as moral, regardless of how common they are among the outgroup (in line with the outgroup irrelevance hypothesis). Importantly, we reverse these tests by examining the interactive effects of ingroup and outgroup members' perceptions of morality on inferences about commonality.

\section{Generalizability of the Link Between Commonality and Morality}

As discussed above, prior work leads to competing predictions about whether outgroup norms matter for participants' own judgments. In addition to testing between these hypotheses, the current work extended prior literature by investigating the generalizability of the perception that common behaviors are moral and vice versa.

First, we varied the perspective of the perceiver, asking participants to make judgments on behalf of another person (third person perspective) as well as themselves (first person perspective). In a number of domains, people expect the third person perspective to differ from the first person perspective, with others making judgments differently than they themselves do. 
For example, people expect their own judgments to be unbiased but expect other people's judgments to be wrought with fallacies (Pronin, 2008). However, in the moral domain, people's own judgments may align closely with the judgments they expect others to make. Indeed, some have argued that a defining feature of moral norms is their universality (Smetana, 2006), which implies that a norm can only qualify as moral if people expect everyone-including themselves and others - to perceive it as such. Unlike other domains in which people presume that others form distinct judgments from themselves, the moral domain may be one in which people expect others to make the same types of judgments as themselves. To disambiguate these possibilities, we tested the extent to which people's expectations regarding others' use of group-based information in norm-based judgments (Studies 1-3) generalized to their own judgments (Study 4).

Second, we tested the extent to which judgments regarding novel groups performing fictitious behaviors (Studies 1-2) generalized to judgments regarding racial groups performing health-related behaviors (Studies 3-4). In contrast to prior studies that tested behaviors that were either fictitious (e.g., "phooshing"; Errikson et al., 2015; Nesdale \& Lawson, 2011) or performed by stick figures or novel groups (e.g. “Glerks”; Lindström et al., 2018; Rhodes \& Chalik, 2013; Roberts, Gelman, \& Ho, 2018; Roberts, Guo, Ho \& Gelman, 2017; Roberts, Ho, \& Gelman, 2017; Roberts, Ho, \& Gelman, 2019), Studies 3-4 asked participants about racial groups and health behaviors. We chose race as a marker of group membership and health behavior as a domain for moral judgments for several reasons. Race is one of the "big three" categories that elicit spontaneous group categorization, and these identities are particularly influential in many social contexts (Brewer, 1988; Fiske, 1998). Since health behaviors frequently vary by racial group (Williams \& Collins, 2001), these behaviors provide an apt context in which to study the 
role of group membership in moral judgments, especially since people often moralize healthrelated behaviors by perceiving some (e.g. exercise) as morally good and others (e.g. illicit drug use) as morally bad (Brandt \& Rozin, 2013).

Furthermore, the use of racial groups and health behaviors has important social consequences. Policy-makers and politicians often rely on public perceptions of behaviors, such as whether using a certain drug should be harshly penalized or whether funding should support the availability of certain foods in schools (Cohen, Tsfati, \& Sheafer, 2008). Oftentimes, these decisions are bolstered by moralized arguments for or against these behaviors (Husak, 2004; Powers, Faden, \& Faden, 2006). Thus, the current studies make important translational contributions.

\section{Overview of Current Studies}

Two experiments (Studies 1-2) and two correlational studies (Studies 3-4) tested whether people are sensitive to outgroup norms when inferring the morality of behaviors based on their commonality among the ingroup and vice versa. The first two studies used fictitious behaviors and novel groups in an effort to isolate the unique effects of outgroup and ingroup norms on judgments. The second two studies used racial groups and health behaviors in order to generalize findings from the first two studies. Additionally, Studies 1-3 asked about participants’ expectations regarding other people's inferences, while Study 4 probed participants' own inferences.

An overview of the study designs can be found in Table 1. We disclose all measures, ${ }^{1}$ manipulations, and exclusions, as well as the method of determining the final sample size. All studies include samples of United States residents. We conducted a priori power analyses prior to

\footnotetext{
1 All measures are uploaded to the following OSF repository: https://osf.io/g3z6y/?view_only=6ce1a8a6236a4b0cb5c3d4930c7076bb. No analyses were conducted on measures not included in this paper.
} 
collecting data for all studies except Study 4, which was the first study we ran in this series. We also conducted post hoc sensitivity analyses, which are discussed below.

\begin{tabular}{|c|c|c|c|c|}
\hline Overview of Stud & Designs & & & \\
\hline $\begin{array}{l}\text { Research } \\
\text { Question }\end{array}$ & Design & Perspective & Target & Main Finding \\
\hline $\begin{array}{l}\text { Study 1: Are } \\
\text { participants } \\
\text { sensitive to } \\
\text { outgroup norms } \\
\text { when using } \\
\text { ingroup } \\
\text { commonality to } \\
\text { infer morality? }\end{array}$ & Experiment & $\begin{array}{l}\text { Other } \\
\text { person }\end{array}$ & $\begin{array}{l}\text { Fictitious person } \\
\text { and fictitious } \\
\text { behaviors }\end{array}$ & $\begin{array}{l}\text { Participants expect } \\
\text { others to perceive that } \\
\text { commonality among } \\
\text { ingroup increases } \\
\text { perceptions of morality } \\
\text { regardless of } \\
\text { commonality among } \\
\text { outgroup }\end{array}$ \\
\hline $\begin{array}{l}\text { Study 2: Are } \\
\text { participants } \\
\text { sensitive to } \\
\text { outgroup norms } \\
\text { when using } \\
\text { ingroup morality } \\
\text { to infer } \\
\text { commonality? }\end{array}$ & Experiment & $\begin{array}{l}\text { Other } \\
\text { person }\end{array}$ & $\begin{array}{l}\text { Fictitious person } \\
\text { and fictitious } \\
\text { behaviors }\end{array}$ & $\begin{array}{l}\text { Participants expect } \\
\text { others to perceive that } \\
\text { morality among ingroup } \\
\text { increases perceptions of } \\
\text { commonality regardless } \\
\text { of morality among } \\
\text { outgroup }\end{array}$ \\
\hline $\begin{array}{l}\text { Study } 3 \text { : Is the } \\
\text { strength of the } \\
\text { association } \\
\text { between } \\
\text { commonality } \\
\text { and morality } \\
\text { stronger for a } \\
\text { target person's } \\
\text { racial ingroup } \\
\text { than outgroup? }\end{array}$ & Correlation & $\begin{array}{l}\text { Other } \\
\text { person }\end{array}$ & $\begin{array}{l}\text { Fictitious person } \\
\text { and real behaviors }\end{array}$ & $\begin{array}{l}\text { Participants expect } \\
\text { others to perceive that } \\
\text { behaviors that are more } \\
\text { common are also more } \\
\text { moral; effect exists for } \\
\text { both ingroups and } \\
\text { outgroups but is } \\
\text { stronger for ingroups }\end{array}$ \\
\hline $\begin{array}{l}\text { Study 4: Is the } \\
\text { strength of the } \\
\text { association } \\
\text { between } \\
\text { commonality } \\
\text { and morality } \\
\text { stronger for a }\end{array}$ & Correlation & Self & $\begin{array}{l}\text { Real person and } \\
\text { real behaviors }\end{array}$ & $\begin{array}{l}\text { Participants perceive } \\
\text { that behaviors that are } \\
\text { more common are also } \\
\text { more moral; effect } \\
\text { exists for both ingroups } \\
\text { and outgroups but is } \\
\text { stronger for ingroups }\end{array}$ \\
\hline
\end{tabular}


target person's

own racial

group?

\section{Study 1: Are participants sensitive to outgroup norms when using commonality to infer morality?}

The purpose of Study 1 was to replicate prior findings showing that perceptions of commonality lead to perceptions of morality (e.g., Eriksson et al., 2015; Lindstrom et al., 2018). We also extended this past work by testing whether the strength of this effect differed depending on the behavioral commonly among both ingroup and outgroup members.

\section{Methods}

Participants. We conducted a power analysis prior to data collection for a $2 \times 2$ factorial ANOVA with alpha $=.05$, power $=0.80$, and an effect size of 0.25 (a conservative estimate; Lakens, 2013), which yielded a sample of 512 participants. Due to participants frequently failing attention checks, to sampling contamination on Amazon Mechanical Turk described elsewhere (Rouse, 2015), and to potential drawbacks of conducting power analyses where the numerator degrees of freedom for the main effect equals the numerator degrees of freedom for the interaction (Giner-Sorolla, 2018), we over-recruited and consented 1,069 people into the study. Participants were screened out if they failed to answer simple attention check questions correctly (i.e. 'to which social group does this person belong?'); therefore, 867 people completed the study. Data from an additional 70 respondents were excluded because they provided an implausible short-response answer at the end (i.e. 'please write in the provided space one of the questions we asked throughout the study'). Here and in all subsequent studies, analyses including all respondents revealed similar patterns of results as those reported below; see Supplementary Materials. Of the remaining 806 people in the sample used for final analyses, 54\% identified as 
female and $46 \%$ identified as male; $72 \%$ identified as White, $9 \%$ identified as Black, and $8 \%$ identified as Asian; 8\% identified as Hispanic or Latinx; and the mean age was 39 years with a range of $18-78$ years. Participants received $\$ 0.20$ for completing the 3-minute study.

Procedure. Participants learned that a fictitious target person belonged to one of two novel groups that lived on a faraway planet. Participants were then randomized into one of four conditions. In the ingroup-common/outgroup-uncommon condition, participants learned that the target person's ingroup members commonly engage in a fictitious behavior and that the target person's outgroup members do not commonly engage in that behavior. For example, participants read: "There are two groups of people on Planet Teeku, the Blarks [ingroup] and the Orps [outgroup]. Joop [target person] is a Blark. On Planet Teeku, Barks flirb [behavior] and Orps do not." The full narrative structure can be found in the Supplementary Materials. Participants then indicated how moral, praiseworthy, and positive Joop thought it was to flirb. These three items were taken from Pizarro, Uhlmann, and Salovey (2003) and combined into a single scale of morality, where $1=$ extremely immoral and 9=extremely moral. All conditions proceeded in this way, such that the ingroup-common/outgroup-common condition contained a common behavior for both the ingroup and the outgroup, the ingroup-uncommon/outgroup-common condition contained a behavior that was uncommon for the ingroup but common for the outgroup, and ingroup-uncommon/outgroup-uncommon condition contained a behavior that was uncommon in both groups. All participants answered a few final demographic questions, were thanked, and received payment for their time.

\section{Results}

A 2 (Ingroup: common vs. uncommon) x 2 (Outgroup: common vs. uncommon) between-subjects ANOVA revealed a main effect for Ingroup $(F(2,801)=759.10, p<.001$, 
$\left.\eta_{\mathrm{p}}{ }^{2}=0.49\right)$, indicating that ratings of morality differed based on how commonly the target person's ingroup members performed the behavior. As can be seen in Figure 1, participants expected targets to perceive behaviors as more moral when they were common $(M=6.92$, $S D=1.66)$, rather than uncommon $(M=3.40, S D=1.93)$, for the target's ingroup. However, the omnibus ANOVA did not reveal a main effect of $\operatorname{Outgroup}\left(F(2,801)=2.84 p=0.092, \eta_{\mathrm{p}}{ }^{2}=0.004\right)$ nor an Ingroup x Outgroup interaction $\left(F(2,801)=0.59, p=.443, \eta_{\mathrm{p}}{ }^{2}=.001\right)$. These findings indicate that the present study did not detect an effect of outgroup norms on perceptions of morality. Post hoc sensitivity analyses revealed that with $80 \%$ power, an alpha error probability of 0.05 , and a sample size of 806 , we would have been able to detect an effect of 0.10 , well below our observed effect.

To better understand how participants reasoned about ingroup versus outgroup norms, we ran simple contrasts to test for differences between conditions in which the ingroup norm remained constant and the outgroup norm varied. The first test compared means for behaviors that were common for the ingroup but either common or uncommon for the outgroup. This test revealed that morality ratings when behaviors were common for both the ingroup and the outgroup $(M=6.97, S D=1.45)$ did not significantly differ from morality ratings when behaviors were common for the ingroup but uncommon for the outgroup $(M=6.86, S D=1.88 ; p=0.517)$. Importantly, the $95 \%$ confidence interval for the difference was narrow, ranging from -0.47 to +0.47 on a 9 -point scale. This implies that the difference in the population was estimated to be at most 0.47 in absolute terms, an amount so small as to suggest that behaviors that were common among the ingroup corresponded to greater perceptions of morality, regardless of whether or not the behavior was common among the outgroup. The second test compared behaviors that were uncommon for the ingroup but varied for the outgroup. Similarly to the previous assessment, 
morality ratings for behaviors that were uncommon among both the ingroup and the outgroup $(M=3.57, S D=1.91)$ did not significantly differ from morality ratings for behaviors that were uncommon among the ingroup but common among the outgroup $(M=3.25, S D=1.94 ; p=0.082)$, with a narrow $95 \%$ confidence interval ranging from -0.66 to +0.66 . Given that the confidence interval includes only very small effects, it appears that outgroup commonality had, at most, a trivial effect on perceptions of morality when behaviors were uncommon for the ingroup.

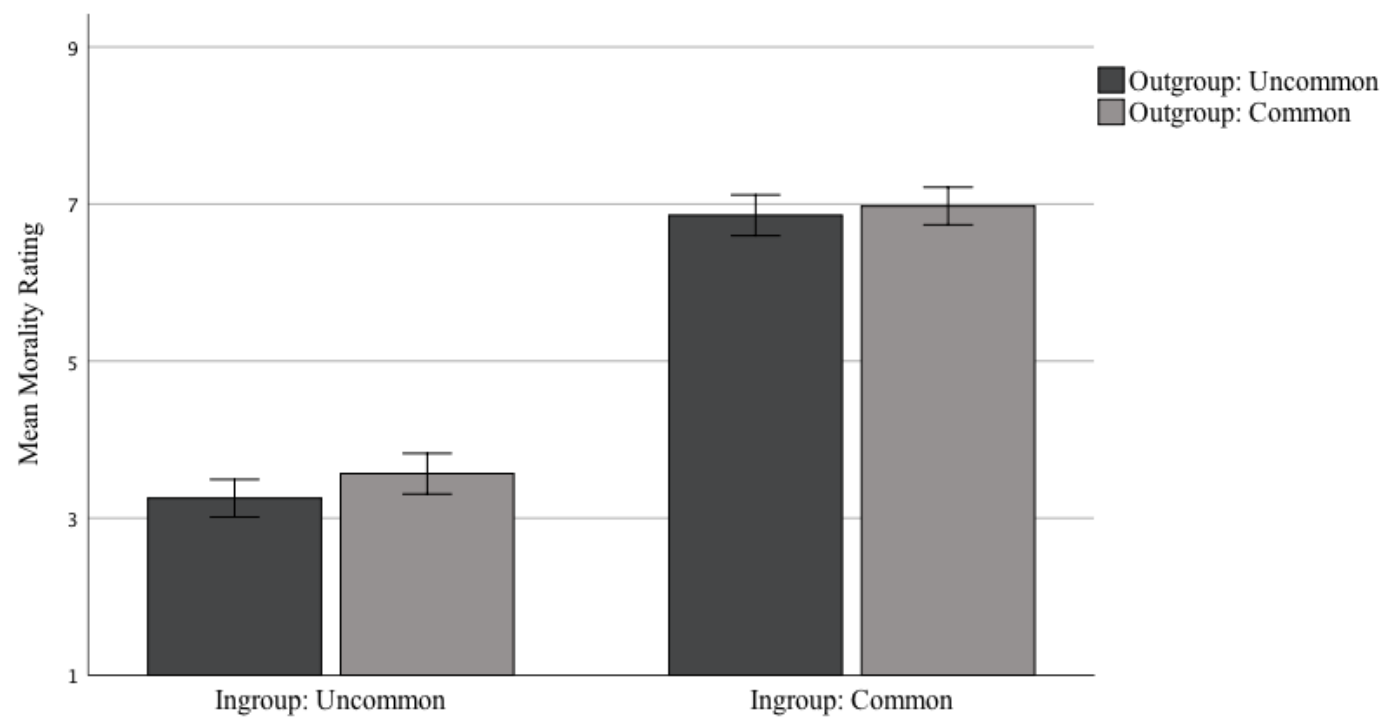

Figure 1: Perceptions of moral valence based on commonality, Study 1. Error bars represent $95 \%$ confidence intervals.

\section{Discussion}

Study 1 tested the extent to which participants expected a target person to view fictitious behaviors as moral on the basis of the behavior's commonality among that target person's ingroup and outgroup members. These results provide the strongest support for the perceived outgroup irrelevance hypothesis, which proposes that information about outgroups does not 
inform participants' judgments. Such findings imply that the common is moral hypothesis does not apply across groups, as behaviors that were common among more groups (and therefore more people) were not perceived as the most moral. Similarly, these data do not support the group differentiation hypothesis, since participants did not necessarily expect the target person to perceive behaviors that were common among the ingroup but not the outgroup to be the most moral.

\section{Study 2: Are participants sensitive to outgroup norms when using morality to infer commonality?}

Study 2 sought to test the reverse causal direction. That is, we probed whether participants expected others to make inferences regarding commonality on the basis of morality and, if so, whether group membership shaped these inferences. Given that most research has manipulated commonality and measured morality (for an exception, see Eriksson et al., 2015), Study 2 provided insight into the understudied but important question of how perceptions regarding morality might influence perceptions regarding commonality. Furthermore, Study 2 like Study 1 -emphasized the relative importance of perceptions regarding ingroup versus outgroup norms.

\section{Methods}

Participants. We used the same a priori power calculation as in Study 1 and aimed to recruit a sample of 512 participants through Amazon Mechanical Turk. To account for potential exclusions and issues mentioned in Study 1 with factorial power analyses, we consented 917 people into the study. As in Study 1, participants were screened out if they failed to answer simple attention check questions correctly (i.e. 'to which social group does this person belong?'); therefore, 661 people completed the study. Data from an additional 121 respondents were 
excluded because these respondents provided an implausible short-response answer at the end (i.e. 'please write in the provided space one of the questions we asked throughout the study'). Of the remaining 540 participants included in final analyses, $57 \%$ identified as female and $43 \%$ identified as male; $76 \%$ identified as White, 10\% identified as Black, and 7\% identified as Asian American; and 9\% identified as Hispanic or Latinx. The mean age was 38 years with a range of 18-75 years. Participants received $\$ 0.20$ for taking the 3-minute survey.

Procedure. The design of this study was identical to Study 1, except that participants learned information about morality and rated their expectations regarding another person's perceptions of commonality. In the ingroup-moral/outgroup-immoral condition, participants learned that the target person's ingroup members viewed a fictitious behavior as moral and that the person's outgroup members viewed the behavior as immoral. For example, participants in this condition read: "There are two groups of people on Planet Teeku, the Blarks [ingroup] and the Orps [outgroup]. Joop [target person] is a Blark. Among Blarks, flirbing [behavior] is considered really moral. Among Orps, flirbing is considered really immoral." Participants then indicated how common Joop thought it was to flirb. The remaining conditions were identical except that those in the ingroup-moral/outgroup-moral condition learned that both groups considered the behavior to be moral, those in the ingroup-immoral/outgroup-moral condition learned that the ingroup considered the behavior to be immoral while the outgroup considered the behavior to be moral, and those in the ingroup-immoral/outgroup-immoral condition learned that both groups viewed the behavior as immoral. All participants then rated how common Joop would believe the behavior to be, from $1=$ Joop believes almost no one engages in the behavior to 9=Joop believes that almost everyone engages in the behavior. All participants answered a few final demographic questions, were thanked, and received payment for their time. 


\section{Results}

We followed the same statistical procedures as in Study 1 and found identical conceptual results. A 2 (Ingroup: moral vs. immoral) x 2 (Outgroup: moral vs. immoral) between-subjects ANOVA revealed a main effect for $\operatorname{Ingroup}\left(F(2,535)=649.32, p<.001, \eta_{\mathrm{p}}{ }^{2}=0.55\right)$, indicating that ratings of morality differed based on commonality for the target person's ingroup. As can be seen in Figure 2, participants expected targets to perceive behaviors as more common when they were moral $(M=7.45, S D=1.70)$, rather than immoral $(M=3.42, S D=1.96)$, for the target's ingroup. However, the omnibus ANOVA did not reveal a main effect of Outgroup $(F(2$, $\left.535)=0.06, p=0.800, \eta_{\mathrm{p}}^{2}<.001\right)$ or an Ingroup $\mathrm{x}$ Outgroup interaction $(F(2,535)=.05, p=0.829$ $\left.\eta_{\mathrm{p}}{ }^{2}<.001\right)$, suggesting that the present study did not detect an effect of outgroup norms influencing perceptions of morality. Post hoc sensitivity analyses revealed that with $80 \%$ power, an alpha error probability of 0.05 , and a sample size of 540 , we would have been able to detect an effect of 0.12 , well below our observed effect.

Following this main analysis, we again ran simple contrasts to test for differences between conditions in which the ingroup norm remained constant and the outgroup norm varied. The first test compared means for behaviors that were moral for the ingroup but either moral or immoral for the outgroup. This test revealed that behaviors that were considered moral by both the ingroup and the outgroup $(M=7.48, S D=1.60)$ did not significantly differ from behaviors that were considered moral by the ingroup but immoral by the outgroup $(M=7.41, S D=1.78$; $p=0.734)$. The $95 \%$ confidence interval for the difference was relatively narrow, ranging from -0.50 to +0.50 on a 9 -point scale. This implies that the difference in the population is estimated to be at most 0.50 in absolute terms, which is negligible. The second test compared behaviors that were immoral for the ingroup but varied for the outgroup. Commonality ratings for 
behaviors that were considered moral by both the ingroup and the outgroup $(M=3.41, S D=1.92)$ did not significantly differ from behaviors that were considered moral by the ingroup but immoral by the outgroup $(M=3.42, S D=2.01 ; p=0.979)$, with a narrow $95 \%$ confidence interval ranging from -0.46 to +0.46 . With confidence intervals that include only very small effects, it appears that outgroup conceptualizations of morality had little to no effect on perceptions of commonality.

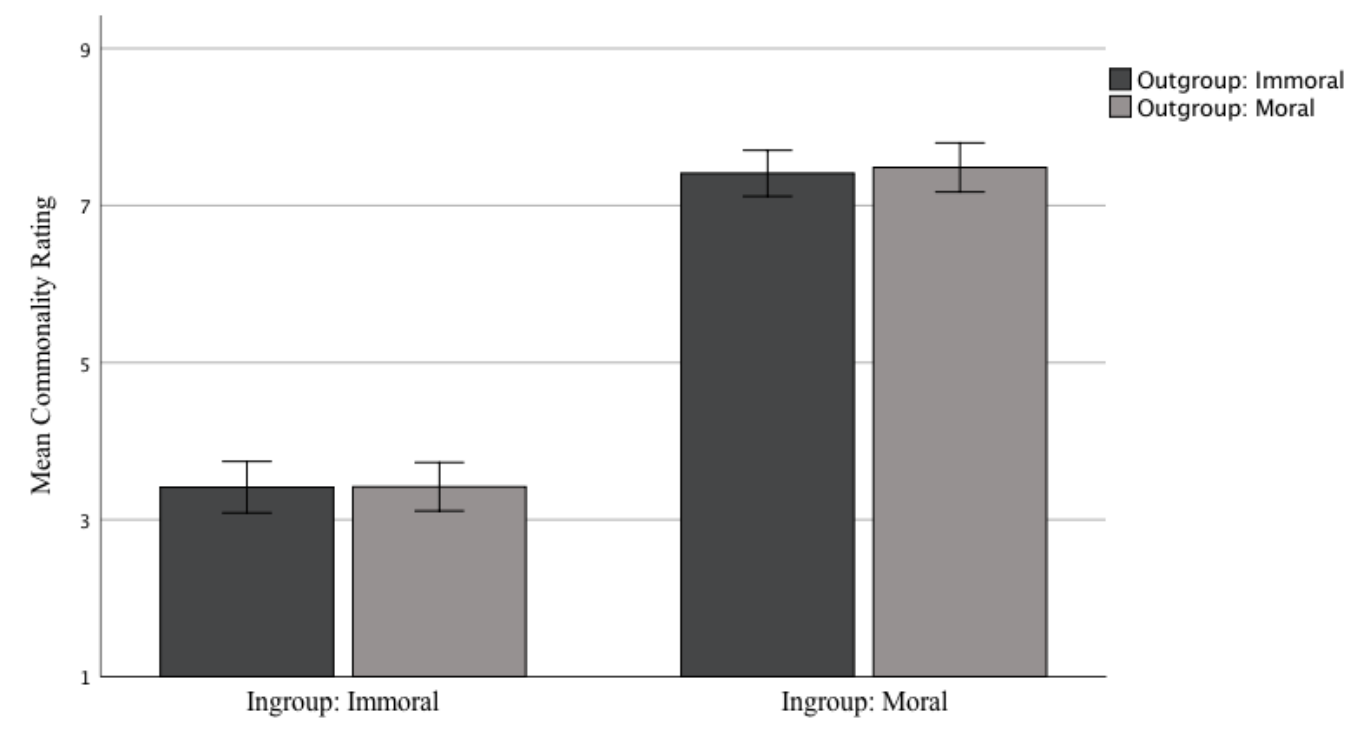

Figure 2: Perceptions of moral valence based on commonality, Study 2. Error bars represent $95 \%$ confidence intervals.

\section{Discussion}

Consistent with Study 1, Study 2 supported the perceived outgroup irrelevance hypothesis by showing that participants attended to ingroup norms, but not outgroup norms, when drawing inferences about the commonality of behaviors. Participants who learned that behaviors were considered to be moral among targets' ingroup members indicated that targets 
would perceive the behavior to be more common, regardless of perceptions among outgroup members. These results suggest that people do not attend to mere consensus about the morality of behaviors (i.e. the common is moral hypothesis in reverse); if they did, then participants in the ingroup-moral/outgroup-moral condition would expect the target person to view the behavior as more common than participants in the ingroup-moral/outgroup-immoral condition. Instead, ratings of commonality were almost identical in these two conditions. Finally, these data did not support the group differentiation hypothesis, as participants did not necessarily expect the target person to perceive behaviors that were considered moral by the ingroup but not the outgroup as the most common.

Studies 1-2 provide several important insights by showing that people expect others to use moral norms among their ingroup to formulate notions of commonality and to use information about commonality to formulate notions of morality, regardless of outgroup norms. Nevertheless, it is unclear whether these types of judgments persist outside of a novel group context. In Studies 1-2, participants only had access to information about perceived commonality (Study 1) and morality (Study 2). These studies therefore traded off higher experimental control at the expense of external validity, and participants may have agreed that behaviors were moral or common because they had no other information on which to judge them. Studies 3-4 therefore utilized real-world social groups and behaviors.

Study 3: Is the strength of the association between commonality and morality stronger for a target person's ingroup than outgroup?

The purpose of Study 3 was to test associations between perceived commonality and morality for real-world social groups and behaviors. Given that Studies 1-2 revealed the bidirectional nature of inferences about commonality and morality, we turned to a correlational 
design to test associations between these constructs for everyday groups and behaviors. This design allowed us to test the bidirectional link between perceptions of commonality and morality while avoiding manipulations that would have required deception and may have seemed unbelievable to participants, such as telling them that Black people find a particular behavior moral while White people find it immoral.

\section{Methods}

Participants. We conducted an a priori power analysis using SimR, inputting prior data that yielded a necessary sample of 250 participants with an $80 \%$ power cutoff. ${ }^{2}$ We overrecruited 268 participants based on completion rates from the prior studies in this paper and the number of participants that our funding allowed us to test. Fifty-four of these participants were excluded for failing one or more simple attention-check questions (e.g. a free-response item at the end of the survey asking them to remember a question that had been presented to them and an image identifier). Of the remaining sample, $52 \%$ identified as female and $48 \%$ identified as male; $81 \%$ identified as White, $11 \%$ identified as Black, and 6\% identified as Asian American; and 7\% identified as Hispanic or Latinx. The mean age was 37 years with a range of 18-70 years. ${ }^{3}$ Participants received $\$ 0.67$ for completing the 10-minute survey.

Procedure. Participants were asked to imagine a White person named Sam. They then learned that they would answer questions about Sam's beliefs and perceptions of various behaviors and that they should do their best to provide the answers that they believed Sam would provide. From Sam's perspective, participants then indicated the percent of White people and Black people who engage in 15 different health behaviors (on a sliding scale from $0 \%$ to $100 \%$ )

\footnotetext{
${ }^{2}$ To conduct the power analysis, we used data from Study 4, which we conducted before Study 3.

${ }^{3}$ Because we did not randomly assign participants to condition and because race-related perceptions vary by age, it is possible that our observed effects were driven by participants' age. To address this, we re-ran the analysis including age as a covariate and found no effect of age. See Supplementary Materials for more information about this analysis.
} 
and reported how moral or immoral Sam would perceive each behavior to be (ranging from 1=extremely immoral to 9=extremely moral). See Table 2 for a list of all behaviors for Studies 34. Since participants learned that Sam was White, all answers for White people represent ingroup beliefs and all answers for Black people represent outgroup beliefs. In order to distract participants from our interest in Sam's supposed perceptions of White compared to Black people who engage in each behavior, 35 filler questions asked about other demographic groups, such as young people. The order of these questions was randomized within blocks, such that participants first rated perceptions of commonality of each behavior among each social category and then indicated perceptions of morality of each behavior. All participants answered a few final demographic questions, were thanked, and received payment for their time.

Table 2: Health Behaviors in Studies 3-4

What percent of [Black/White/filler group] people...

...sleep at least 7 hours per night, on average?

...have ever smoked crack cocaine?

...have smoked marijuana in the past month?

...consume more than $40 \%$ of their calories from calorie dense (junk) foods and drinks?

...get sufficient exercise (at least $2.5 \mathrm{hrs}$ of moderate or $1.25 \mathrm{hrs}$ of vigorous activity per week)?

...have ever had risky unprotected sex?

...have smoked 100 cigarettes or fewer in their lifetime?

...drink enough water daily (3.7 liters for men and 2.7 liters for women)?

...east less than one fruit daily?

...drink alcohol heavily (more than 7 drinks per week [women], or more than 14 drinks per week [men], on average, in the past year)?

...abused prescription opioids in the last year?

...have ever done heroin?

...have ever done powder cocaine? 
...got the flu shot last year?

...take medications as prescribed by a doctor?

\section{Analytic Strategy}

Since each person answered 15 questions about the percent of White people who perform each behavior, the percent of Black people who perform each behavior, and the moral valence of each behavior, the data contained observations nested within participants. This data structure necessitated multilevel modeling. We therefore specified and estimated a multilevel mixed model using R Statistical software and the nlme package with the default estimation procedure, maximum likelihood estimation. In line with established recommendations (Bolger \& Lauranceau, 2013), we disaggregated the within- and between-person levels of continuous variables prior to running the model. Moreover, we estimated random effects for intercepts but not for slopes. For interpretability purposes, we re-scaled the morality variable to be between 0 and 100.

We regressed ratings of morality on a $0 / 1$ indicator variable for ingroup ( 1 =ingroup), the percent of people perceived to perform behaviors (i.e. commonality), and an interaction term between ingroup and estimated percents. Since outgroup was coded as zero, the coefficient for the percent of people performing each behavior revealed the association between the perceived commonality of a behavior among the outgroup and perceived morality; a positive coefficient would suggest that participants expected Sam to perceive that behaviors that were more common among Sam's outgroup to also be more moral. The interaction term revealed the additional effect of ingroup commonality on perceptions of morality; a positive interaction term would imply that the strength of the association between commonality and morality was stronger for ingroup 
norms than for outgroup norms. We also ran a simple slopes analysis to determine whether the association between ingroup commonality and perceptions of morality significantly differed from zero.

\section{Results}

Results can be found in Table 3, and a visualization can be found in Figure 3. Since between-person fixed effects in this setting are not entirely interpretable (e.g. we were not interested in differences in morality scores for people who rated all behaviors as more or less common than the group mean), we represent and interpret only the within-person fixed effects. Results revealed an association between commonality on morality that was moderated by group membership. When participants made judgments on behalf of another person, an association between outgroup commonality and perceptions of morality emerged. Participants indicated, on average, that a $10 \%$ increase in the percent of outgroup members who engaged in a behavior was associated with an increase of about 2 points out of 100 on the morality scale $(b=0.20, p<.001)$. Simple slopes analyses also revealed an association between ingroup commonality and perceptions of morality. Participants indicated, on average, that a $10 \%$ increase in the percent of ingroup members who engaged in a behavior was associated with an increase of about 3 points out of 100 on the morality scale $(b=0.28, p<.001)$. This association was significantly stronger than that between outgroup commonality and morality $(b=0.08, p=.005)$. In other words, the link between perceptions of commonality and morality was slightly positive for outgroup members and even more positive for ingroup members. A simulated post-hoc sensitivity analytic approach (in the $\operatorname{sim} R$ package) revealed that with $80 \%$ power, an alpha error rate of 0.05 , and a sample size of 214, we were able to detect an effect as small as 0.08 - on par with the effect we observed in this study. 
Table 3: Multilevel Mixed Model, Study 3

\begin{tabular}{|l|c|c|c|}
\hline Fixed effects & Estimate & $\mathrm{SE}$ & $\mathrm{t}$ \\
(intercept, slopes) & & 0.7 & $63.8^{* *}$ \\
\hline Intercept & 42.72 & 0.7 & 0.9 \\
Ingroup (1=yes) & 0.63 & 0.02 & $9.2^{* *}$ \\
Percent & 0.20 & 0.03 & $2.8^{*}$ \\
\hline Ingroup*Percent & 0.08 & \\
\hline
\end{tabular}

$* p<.05, * * p<.001$
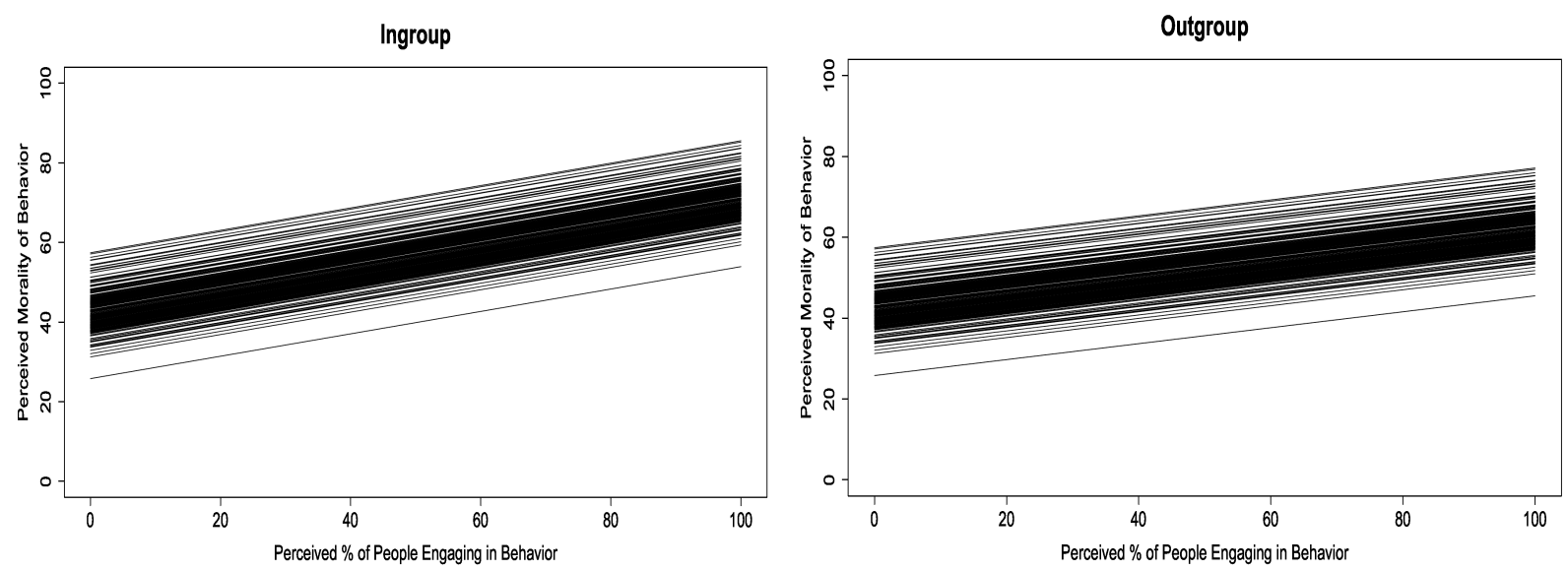

Figure 3: Association between the percent of people perceived to engage in a behavior and that behavior's perceived morality in Study 3, in which participants answered from the viewpoint of another person. Each line represents a model-predicted intercept and slope for each person in the dataset. Note that the morality index was rescaled to be between 0 and 100 .

\section{Discussion}

The main goal of Study 3 was to test the association between commonality and morality, with a specific interest in whether the association was stronger for a target person's ingroup relative to a target person's outgroup. By asking participants to respond on behalf of another person, we gained insight into participants' expectations of others' judgments regarding morality and commonality. Participants expected another person to perceive behaviors that were more common among their outgroup as more moral. This association between commonality and morality was stronger for ingroup norms.

Since commonality and morality were more strongly linked for ingroup versus outgroup norms, these data provide some support for the perceived outgroup irrelevance hypothesis. 
However, the fact that participants did not completely ignore information about the outgroup implies a more tempered interpretation; namely, participants may have perceived the outgroup as less relevant rather than as completely irrelevant. Indeed, the fact that outgroup commonality correlated with perceptions of morality while holding constant the effect of ingroup commonality partially supports the common is moral hypothesis, which proposes that perceptions of commonality and morality will be positively associated, which is the case for behaviors common among both the ingroup and the outgroup. At the same time, these results provide a third set of data (in conjunction with Studies 1-2) that fail to support the group differentiation hypothesis, which would predict a shallower slope between outgroup commonality and morality than that between ingroup commonality and morality. Taken together, these data suggest a nuanced process whereby perceptions regarding outgroup commonality are associated with perceptions of morality to some extent, but not as much as perceptions regarding ingroup commonality.

Despite these contributions to the literature, Study 3 also had several limitations. For instance, it is possible that this pattern of results is specific to expectations of other people and would not generalize to participants' own judgments. Further, the sample was largely White, which constitutes a limitation for several reasons. First, the proportion of White participants in psychology studies is larger than White people's representation in the population, perhaps due in part to the fact that psychological studies are conducted largely by White researchers (Does et al., 2018; Roberts, Bareket-Shavit, Dollins, Goldie, \& Mortenson, 2020). Although this limitation is not specific to Study 3, it is an important one to address so that psychological science can better speak to the experiences of diverse groups of people. Second, testing largely White participants introduced a potential ambiguity into the results. Because the target person, Sam, was described as White, participants responded on behalf of a person for whom ingroup 
members were high in perceived racial status (Kahn, Ho, Sidanius, \& Pratto, 2009). Therefore, it is unclear whether the underlying cognitive process reflects effects of group status (high versus low, reflecting stereotypes that individuals high in racial status are also particularly moral) or group membership (ingroup versus outgroup, reflecting a perception that ingroup norms are particularly moral). Study 4 addressed these limitations by asking Black and White participants about their own perceptions of commonality and morality.

\section{Study 4: Is the strength of the association between commonality and morality stronger for}

\section{a target person's own racial group?}

Study 4 built on the results in Studies 1-3 by asking people to report their own judgments regarding commonality and morality rather than their expectations regarding others' judgments. Further, Study 4 recruited both Black and White participants to expand the diversity of psychological science and further probe why group-based information may play a role in perceptions regarding morality and commonality.

Participants. In an effort to test a more diverse sample, we recruited participants through Amazon Mechanical Turk and Toolkit platforms, the latter of which allows for special sampling of pre-specified populations. A total of 127 participants completed the online survey. ${ }^{4}$ Twentytwo of these participants were excluded for failing the same attention check questions as in Study 3. Ten additional participants were excluded for not identifying as either White or Black. Of the 95 participants remaining, 55\% identified as female and $45 \%$ identified as male; $52 \%$ identified as White and $48 \%$ identified as Black. The mean age was 35 with a range of 22-68 years. ${ }^{5}$

Participants received $\$ 0.67$ for taking the 10-minute survey.

\footnotetext{
${ }^{4}$ We performed Study 4 first in this series of studies. Because we lacked results from the other studies in this paper on which to base an estimate of the expected effect size, we aimed for a final sample of 100 participants.

${ }^{5}$ As in Study 3, we re-ran analyses with age as a covariate and found that the results remained consistent. See Supplementary Materials.
} 
Procedure. The procedure was identical to Study 3, except that participants provided their own perceptions of the percent of White people and Black people who engage in 15 different health behaviors (ranging from $0 \%$ to $100 \%$ ) and the moral valence of each behavior (ranging from $1=$ extremely immoral to $9=$ extremely moral). We again included 35 filler questions asking about the percent of other demographic groups so as to distract from our interest in racial groups. Thus, for Black participants all answers about Black people served as ingroup information and all answers about White people served as outgroup information, whereas the reverse was true for White participants. The order of these questions was randomized within blocks, such that participants first rated perceptions of commonality of each behavior among each social category and then indicated how moral they perceived each behavior to be. After completing the survey, participants answered a few final demographic questions, were thanked, and received payment for their time.

\section{Results}

We used a similar statistical analysis as in Study 3. We regressed ratings of morality on a 0/1 indicator variable for participant race (1=Black), a 0/1 indicator variable for group ( $1=$ ingroup), the percent of people perceived to perform behaviors (i.e. commonality), and an interaction term between group and estimated percents. The coefficient for the $0 / 1$ race variable controlled for the effect of participant race. Since outgroup was coded as zero, the coefficient for the percent of people performing each behavior revealed the association between the perceived commonality of a behavior among the outgroup and perceived morality; a positive coefficient would suggest that participants perceived that behaviors that were more common among their outgroup were also more moral. The interaction term revealed the additional effect of ingroup commonality on perceptions of morality; a positive interaction term would again imply that the 
strength of the association between commonality and morality was stronger for ingroup norms than for outgroup norms. We also ran a simple slopes analysis to determine whether the association between ingroup commonality and perceptions of morality significantly differed from zero.

Results can be found in Table 4, and a visualization can be found in Figure 4. Since between-person fixed effects in this setting are not entirely interpretable (e.g. we were not interested in differences in morality scores for people who rated all behaviors as more or less common than the group mean), we again represent and interpret only the within-person fixed effects. This model revealed an association between perceptions of commonality and morality that was again moderated by social groups. Participants indicated, on average, that a $10 \%$ increase in the percent of outgroup members who engaged in a behavior was associated with an increase of about 3 points out of 100 on the morality scale $(b=0.27, p<.001)$. Simple slopes analyses also revealed an association between ingroup commonality and perceptions of morality. In this case, participants indicated, on average, that a $10 \%$ increase in the percent of ingroup members who engaged in a behavior was associated with an increase of about 4 points out of 100 on the morality scale $(b=0.38, p<.001)$. This association was significantly stronger than that between perceptions of outgroup commonality and morality $(b=0.11, p=.014)$. In other words, the association between perceptions of commonality and morality was slightly positive for outgroup members and more positive for ingroup members. A simulated post-hoc sensitivity analytic approach (in the simR package) revealed that with $80 \%$ power, an alpha error rate of 0.05 , and a sample size of 95 , we were only able to detect an effect as small as 0.125 . The results should therefore be interpreted with some caution, as the effect that we observed was somewhat 
smaller $(b=0.11)$. Nonetheless, the consistency of these results with those of Studies 1-3 can increase confidence in these results.

We also conducted a supplementary analysis examining whether race (participants answering questions about Black versus White individuals), rather than group membership (participants answering questions about ingroup versus outgroup members), explained the results. We did not find such an effect; see Supplementary Materials for additional details.

Table 4: Multilevel Mixed Model, Study 4

\begin{tabular}{|l|c|c|c|}
\hline $\begin{array}{l}\text { Fixed effects } \\
\text { (intercept, slopes) }\end{array}$ & Estimate & $\mathrm{t}$ \\
\hline Intercept & 46.08 & 1.28 & $36.3^{* *}$ \\
Participant Race (1=Black) & -1.47 & 1.69 & -0.87 \\
Ingroup (1=yes) & 0.58 & 1.02 & 0.56 \\
Percent & 0.27 & 0.03 & $8.5^{* *}$ \\
Ingroup*Percent & 0.11 & 0.04 & $2.4^{*}$ \\
\hline
\end{tabular}

$* p<.05, * * p<.001$
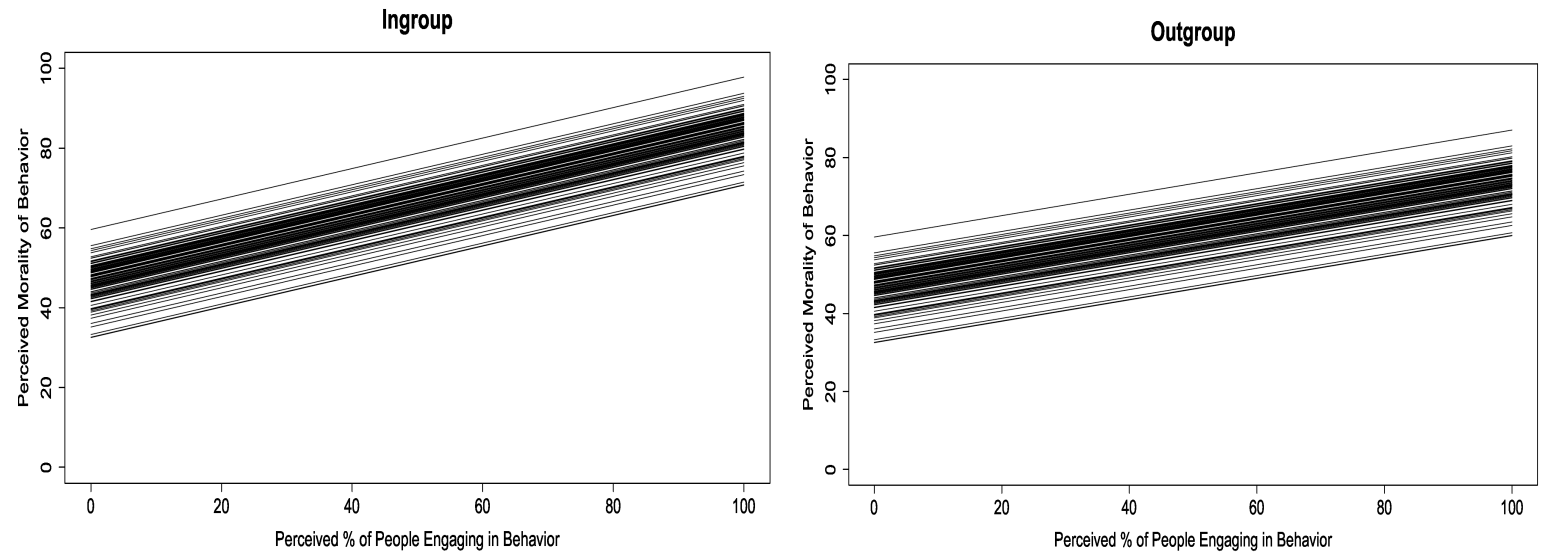

Figure 4: Association between the percent of people perceived to engage in a behavior and that behavior's perceived morality, Study 4 . Each line represents a model-predicted intercept and slope for each person in the dataset. Note that the morality index was rescaled to be between 0 and 100.

\section{Discussion}


These data replicate and extend the findings from Study 3. Consistent with Study 3, Study 4 revealed a statistically reliable association between perceptions of commonality and morality that was stronger when participants answered questions about ingroup versus outgroup members. In other words, both Black and White participants perceived that behaviors that were more common among their outgroup were also more moral. However, this association was stronger for behaviors that they perceived as common among their ingroup. These findings again provide partial support for the perceived outgroup irrelevance hypothesis by showing that participants' judgments depended less on perceptions of outgroup members. At the same time, these findings also provide partial support for the common is moral hypothesis, as the association between perceived commonality and perceived morality emerged for perceptions of both ingroups and outgroups to some extent. As in Study 3, we failed to find support for the group differentiation hypothesis, which would have predicted opposing effects for perceptions of ingroup versus outgroup members.

These results echo the patterns obtained from a third-party perspective in Studies 1-3 and suggest that such findings generalize to a first-person perspective. This converging evidence strengthens the conclusion that norm-based judgments depend on group membership.

\section{General Discussion}

We investigated the extent to which people are sensitive to information about outgroup norms when inferring that common behaviors are moral and vice versa. Four studies tested between three theory-driven hypotheses. On the one hand, people's judgments of commonality and morality could depend on both ingroup and outgroup norms. This could occur either as an extension of people's sensitivity to behavioral frequency information in their social environments (i.e. the common is moral hypothesis, which implies that individuals perceive 
behaviors that are common among more people to be the most moral) or as a way to further differentiate groups (i.e. the group differentiation hypothesis, which implies that behaviors that are common among a person's ingroup but uncommon among that person's outgroup are perceived to be the most moral). On the other hand, perceptions could be insensitive to outgroup norms, such that people pay attention mostly to commonality and morality among their ingroup (the perceived outgroup irrelevance hypothesis). This possibility stems from prior work showing that adults do not always align their behavior or attitudes with outgroup members (Smith \& Louis, 2008; for slightly different results with children and adolescents suggesting that younger participants may attend more to outgroup norms, see McGuire, Manstead, \& Rutland, 2017). Studies 1-2 provided strong support for the perceived outgroup irrelevance hypothesis. Studies 3-4 provided some additional support for this hypothesis while also providing some evidence in favor of the common is moral hypothesis. Taken together, these results indicate that outgroup norms are less relevant than ingroup norms but do contribute to perceptions of 'more common' and therefore 'more moral' across groups.

\section{Theoretical Implications}

As discussed above, results from Studies 1-2 supported the perceived outgroup irrelevance hypothesis. In Study 1, participants expected a target person to infer that behaviors that were common among that person's ingroup were also moral, regardless of how common those behaviors were among that person's outgroup. Study 2 tested the reverse causal pathway. Here, participants expected a target person to infer that behaviors were more common if that target's ingroup perceived those behaviors as moral, regardless of moral perceptions among the target's outgroup. These results support the perceived outgroup irrelevance hypothesis since outgroup norms seemed to have no impact on socio-moral cognition. 
However, results from Studies 3-4 suggest that this conclusion should be tempered, as outgroup norms were associated with participants' judgments to some extent, albeit not as much as ingroup norms. Participants expected others to perceive common behaviors as more moral (Study 3), and participants themselves also shared this perception (Study 4). This effect emerged when participants considered both ingroup and outgroup norms, although it was stronger in the former case. This finding suggests that outgroup norms may not be completely irrelevant in everyday contexts involving actual behaviors and social groups (as compared with fictitious behaviors and novel groups, as tested in Studies 1-2). Thus, these data partially support the common is moral hypothesis, as participants perceived (and expected others to perceive) more common behaviors to be more moral regardless of whether those behaviors were perceived as particularly common among ingroup or outgroup members. At the same time, ingroup norms were more strongly associated with participants' judgments than outgroup norms. This result may have emerged because individuals typically perceive ingroup members as more similar to themselves than outgroup members (Imhoff \& Dotsch, 2013) and may therefore find ingroup norms to be more informative for how they should behave and what they should believe. Thus, Studies 3-4 also provided some support for the perceived outgroup irrelevance hypothesis.

Taken together, these results highlight the importance of generalizing experimental findings beyond the lab. If we only had data from Studies 1-2, it would be reasonable to conclude that support emerged only for the outgroup irrelevance hypothesis. The additional results from Studies 3-4 help to temper this conclusion by showing somewhat weaker support for this hypothesis in conjunction with some support for the common is moral hypothesis.

The fact that commonality and morality were bidirectionally linked from both a first- and third-party perspective contributes to the broader literature on moral cognition, which has 
focused primarily on the influence of norms from one's own perspective (for a notable exception, see Patil, Young, Sinay, \& Gleichgerrcht, 2017). According to several theories of moral cognition, a defining feature of morality is the notion that moral norms are consistent for everyone, including the self and others (Schwartz, 2007; Schwartz \& Bardi, 2001; Smetana, 2006; Turiel, 1978). Therefore, we tested the role of group membership both in people's own judgments and in their expectations regarding others' judgments. The fact that we found parallel results when asking people to make judgments on behalf of themselves and another person supports the idea that in the domain of morality, individuals may expect others to form similar judgments as those they themselves make. This process differs from prior results in other domains, in which people expected differences between their own and others' judgments (e.g. Pronin, 2008).

The current studies also add theoretical insight to the literature on group processes. By now, it is well known that people's attitudes toward and evaluations of others depend on group membership (e.g. Fiske, Cuddy, Glick, \& Xu, 2002; Gaertner \& Dovidio, 2005; Heiphetz \& Young, 2019; Richeson \& Nussbaum, 2004; Tajfel et al., 1979). However, this work has paid less attention to the role that group membership may play in judgments that do not, on their face, appear to be about groups at all (e.g. how common particular behaviors are). Our results indicate that people's norm-based judgments are more sensitive to information about members of their ingroup rather than their outgroup. In other words, participants appeared to judge — and expected others to judge - behaviors that were common among their ingroup to be more moral and behaviors that were more moral among their ingroup to be more common for everyone. However, information about how common or moral behaviors were among the perceiver's 
outgroup played a smaller role in social judgment. This set of findings is among the first to show the role that group-based information plays in cognition broadly construed.

\section{Translational Implications}

In addition to the theoretical contributions discussed above, these findings are likely to be useful as researchers, policy-makers, and advertisers increasingly utilize norm-based information to nudge behavior. In their pioneering work on norms and behavior, Cialdini and colleagues (1990) argued that people align their behaviors to mirror both what others actually do and what others should do, depending on which norm is salient. For example, a person who enters a clean environment is far less likely to litter than a person who enters a littered environment, suggesting that behavior is highly sensitive to common norms. Researchers have applied this influential finding to a number of contexts, including environmental behaviors (Lindenberg \& Steg, 2007), attitudes toward existential threat (Jonas et al., 2008; Louis \& Taylor, 2002), and helping behavior (Bendapudi, Singh, \& Bendapudi, 1996).

The current studies suggest that these effects could depend on whether people perceive that an ingroup or an outgroup constitutes the norm. For example, people may be more likely to wear a face mask during a pandemic when they know or presume that their ingroup wears them. This idea is particularly relevant as this article goes to press in Summer $2020^{6}$ and emerging public health messages frame health behaviors such as mask wearing as highly common among certain political groups (i.e. Democrats) and less so among others (i.e. Republicans; Gallup, 2020). Our results imply that such group-based messaging is likely effective for the group(s) among whom the behavior is portrayed as common; however, such messages are likely less effective for the group(s) among whom the behavior is portrayed as uncommon. One potential

\footnotetext{
${ }^{6}$ We thank our action editor for suggesting that we discuss the implications of our findings for current events.
} 
path forward is to highlight commonality among a larger group (e.g., to note that wearing masks is common among Americans).

At the same time, the results from Studies 3-4 suggest that inferences between commonality and morality are not entirely constrained to the ingroup. This is an important finding in light of increasing racial diversity among protestors in the United States concerning police violence and systemic racism (Pew Research Center, 2020). Our results imply that diverse protests may change moral judgments among a greater number of people than protests that include primarily one group.

\section{Limitations and Future Directions}

In addition to the contributions the current work makes to psychological theories and practice, it also contains several limitations. The effect sizes are relatively small, which implies that commonality is unlikely to be the only factor influencing perceptions of morality and vice versa. Nevertheless, these effects emerged reliably across four studies, suggesting that the association between perceptions of commonality and morality is consistent and reliable, albeit stronger for the ingroup (for further discussion of the importance of small effect sizes, see Greenwald, Banaji, \& Nosek, 2015; Prentice \& Miller, 1992).

Additionally, we did not directly manipulate the status of the outgroup across all of our studies, and future work could test whether the status of the outgroup influences norm-based judgments. It could be that some types of group differences actually reverse the findings reported here. For instance, some research on benevolent sexism suggests that men may see women as particularly moral (Glick \& Fiske, 2018). Future research should explore the boundary conditions of the effects presented here, including whether these effects are moderated by levels of ingroup identification (see Brewer, 2001), as prior research indicates that identity-relevance 
plays a role in the relative importance of ingroup moral norms (Christensen, Rothgerber, Wood, \& Matz, 2004).

Finally, we recruited Amazon Mechanical Turk participants in our studies in order to obtain large samples. This choice allowed us to recruit a more diverse group of participants than sampling locally, including participants varying in age, geographical location, and race (particularly in Study 4). Future work can determine the extent to which the findings reported here generalize to individuals who are not represented by this sampling strategy, such as people who lack Internet access or people residing in other countries (see Roberts et. al, 2017 for generalizability and differences in the common-moral association across cultures).

\section{Conclusion}

Prior work has shown that people infer morality from commonality (Lindström et al., 2018; Roberts, Gelman, \& Ho, 2018; Roberts, Guo, Ho \& Gelman, 2017; Roberts, Ho, \& Gelman, 2017; Roberts, Ho, \& Gelman, 2019; Tworek \& Cimpian, 2016) and visa versa (Eriksson et al., 2015). Furthermore, such judgments may depend on the norms (Abrams, Rutland \& Cameron, 2003; Nesdale \& Lawson, 2011) and behaviors (Rhodes \& Chalik, 2013; Roberts, Gelman, \& Ho, 2018; Roberts, Guo, Ho \& Gelman, 2017; Roberts, Ho, \& Gelman, 2017; Roberts, Ho, \& Gelman, 2019) of a person's ingroup members. The current studies built on this research by investigating how people incorporate outgroup norms in these inferences. Four studies showed that people attend more to ingroup rather than outgroup norms when making judgments about commonality and morality and that they expect others to do the same. However, these effects emerged more reliably in controlled experimental contexts and were more nuanced in real-world contexts, where outgroup norms did matter to some extent, albeit less than ingroup norms. From a theoretical perspective, these findings imply that a strict 
'common is moral' heuristic may need to be revised and that social group information moderates the effects of norm-based reasoning. From a translational perspective, these findings imply that efforts to nudge behavior based on norms should also incorporate information about the social groups constituting those norms. 


\section{References}

Abele, A. E., Hauke, N., Peters, K., Louvet, E., Szymkow, A., \& Duan, Y. (2016). Facets of the fundamental content dimensions: Agency with competence and assertivenessCommunion with warmth and morality. Frontiers in Psychology, 7, 1810.

Abrams, D., Rutland, A., \& Cameron, L. (2003). The development of subjective group dynamics: Children's judgments of normative and deviant in-group and out-group individuals. Child development, 74, 1840-1856.

Bear, A., \& Knobe, J. (2017). Normality: Part descriptive, part prescriptive. Cognition, 167, 2537.

Bendapudi, N., Singh, S. N., \& Bendapudi, V. (1996). Enhancing helping behavior: An integrative framework for promotion planning. Journal of Marketing, 60, 33-49.

Bolger, N., \& Laurenceau, J. P. (2013). Intensive longitudinal methods: An introduction to diary and experience sampling research. Guilford Press.

Brandt, A. M., \& Rozin, P. (2013). Morality and Health. Florence: Taylor and Francis.

Brambilla, M., \& Leach, C. W. (2014). On the importance of being moral: The distinctive role of morality in social judgment. Social Cognition, 32, 397-408.

Brewer, M. B. (2001). Ingroup identification and intergroup conflict. Social identity, intergroup conflict, and conflict reduction, 3, 17-41.

Brewer, M. B. (1988). A dual process model of impression formation In: RS Wyer \& TK Srull( Eds) Advances in Social Cognition (pp. 1-36). Hillsdale, NJ: Lawrence Erlbaum Associates. 
Christensen, P. N., Rothgerber, H., Wood, W., \& Matz, D. C. (2004). Social norms and identity relevance: A motivational approach to normative behavior. Personality and Social Psychology Bulletin, 30, 1295-1309.

Cialdini, R. B., Reno, R. R., \& Kallgren, C. A. (1990). A focus theory of normative conduct: Recycling the concept of norms to reduce littering in public places. Journal of Personality and Social Psychology, 58, 1015-1026.

Cohen, J., Tsfati, Y., \& Sheafer, T. (2008). The influence of presumed media influence in politics: Do politicians' perceptions of media power matter? Public Opinion Quarterly, 72, 331-344.

Costa, P. T., Terracciano, A., \& McCrae, R. R. (2001). Gender differences in personality traits across cultures: Robust and surprising findings. Journal of Personality and Social Psychology, 81, 322-331.

De Freitas, J., \& Cikara, M. (2018). Deep down my enemy is good: Thinking about the true self reduces intergroup bias. Journal of Experimental Social Psychology, 74, 307-316.

Does, S., Ellemers, N., Dovidio, J. F., Norman, J. B., Mentovich, A., van der Lee, R., \& Goff, P. A. (2018). Implications of research staff demographics for psychological science. American Psychologist, 73, 639.

Eriksson, K., Strimling, P., \& Coultas, J. C. (2015). Bidirectional associations between descriptive and injunctive norms. Organizational Behavior and Human Decision Processes, 129, 59-69.

Fiske ST. (1998). Stereotyping, prejudice, and discrimination. In: Gilbert DT, Fiske ST, \& Lindzey G (Eds). The Handbook of Social Psychology (pp. 357-411). Boston, MA: McGraw-Hill. 
Fiske, S. T. (2018). Warmth and competence are parallels to communion and agency: Stereotype content model. In Agency and Communion in Social Psychology (pp. 39-51). Routledge.

Fiske, S. T., Cuddy, A. J., Glick, P., \& Xu, J. (2002). A model of (often mixed) stereotype content: competence and warmth respectively follow from perceived status and competition. Journal of Personality and Social Psychology, 82, 878-902.

Gallup Poll (2020). “New April guidelines boost perceived efficacy of masks.” May 13, 2020. Retrieved from https://news.gallup.com/poll/310400/new-april-guidelines-boostperceived-efficacy-face-masks.aspx

Giner-Sorolla, R. (2018, January 24). Powering your interaction [web blog post]. Retrieved from https://approachingblog.wordpress.com/2018/01/24/powering-your-interaction-2/

Glick, P., \& Fiske, S. T. (2018). The ambivalent sexism inventory: Differentiating hostile and benevolent sexism. In Social Cognition (pp. 116-160). Routledge.

Greenwald, A. G., Banaji, M. R., \& Nosek, B. A. (2015). Statistically small effects of the Implicit Association Test can have societally large effects. Journal of Personality and Social Psychology, 108, 553-561.

Haidt, J. (2013). The righteous mind: Why good people are divided by politics and religion. New York: Vintage Books.

Hall, N. R., \& Crisp, R. J. (2008). Assimilation and contrast to group primes: The moderating role of ingroup identification. Journal of Experimental Social Psychology, 44, 344-353.

Heinrichs, N., Rapee, R. M., Alden, L. A., Bögels, S., Hofmann, S. G., Oh, K. J., \& Sakano, Y. (2006). Cultural differences in perceived social norms and social anxiety. Behaviour Research and Therapy, 44, 1187-1197. 
Heiphetz, L., \& Young, L. L. (2019). Children's and adults' emotional generosity toward members different religious groups. American Behavioral Scientist.

Heiphetz, L., Strohminger, N., Gelman, S. A., \& Young, L. L. (2018). Who am I? The role of moral beliefs in children's and adults' understanding of identity. Journal of Experimental Social Psychology, 78, 210-219.

Husak, D. N. (2004). The moral relevance of addiction. Substance use \& misuse, 39, 399-436.

Hume, D. (2003). A treatise of human nature. Chelmsford, MA: Courier Corporation.

Hysenbelli, D., Rubaltelli, E., \& Rumiati, R. (2013). Others' opinions count, but not all of them: anchoring to ingroup versus outgroup members' behavior in charitable giving. Judgment \& Decision Making, 8, 678-690.

Imhoff, R., \& Dotsch, R. (2013). Do we look like me or like us? Visual projection as self-or ingroup-projection. Social Cognition, 31, 806-816.

Jonas, E., Martens, A., Niesta, D., Fritsche, I., Sullivan, D., \& Greenberg, J. (2008). Focus theory of normative conduct and terror-management theory: The interactive impact of mortality salience and norm salience on social judgment. Journal of Personality and Social Psychology, 95, 1239-1251.

Kahn, K., Ho, A. K., Sidanius, J., \& Pratto, F. (2009). The space between us and them: Perceptions of status differences. Group Processes \& Intergroup Relations, 12, 591-604.

Lakens, D. (2013). Calculating and reporting effect sizes to facilitate cumulative science: a practical primer for t-tests and ANOVAs. Frontiers in Psychology, 4, 1-12.

Leach, C. W., Bilali, R., \& Pagliaro, S. (2015). Groups and morality. APA Handbook of Personality and Social Psychology, 2, 123-149. 
Lindenberg, S., \& Steg, L. (2007). Normative, gain and hedonic goal frames guiding environmental behavior. Journal of Social Issues, 63, 117-137.

Lindström, B., Jangard, S., Selbing, I., \& Olsson, A. (2018). The role of a "common is moral" heuristic in the stability and change of moral norms. Journal of Experimental Psychology: General, 147, 228-242.

Louis, W. R., \& Taylor, D. M. (2002). Understanding the September 11 terrorist attack on America: The role of intergroup theories of normative influence. Analyses of Social Issues and Public Policy, 2, 87-100.

McGuire, L., Manstead, A. S., \& Rutland, A. (2017). Group norms, intergroup resource allocation, and social reasoning among children and adolescents. Developmental Psychology, 53, 2333-2339.

Mu, Y., Kitayama, S., Han, S., \& Gelfand, M. J. (2015). How culture gets embrained: Cultural differences in event-related potentials of social norm violations. Proceedings of the National Academy of Sciences, 112, 15348-15353.

Newman, G. E., Bloom, P., \& Knobe, J. (2014). Value judgments and the true self. Personality and Social Psychology Bulletin, 40, 203-216.

Nesdale, D., \& Lawson, M. J. (2011). Social groups and children's intergroup attitudes: Can school norms moderate the effects of social group norms?. Child development, 82, 15941606.

Patil, I., Young, L., Sinay, V., \& Gleichgerrcht, E. (2017). Elevated moral condemnation of third-party violations in multiple sclerosis patients. Social Neuroscience, 12, 308-329. 
Perdue, C. W., Dovidio, J. F., Gurtman, M. B., \& Tyler, R. B. (1990). Us and them: social categorization and the process of intergroup bias. Journal of Personality and Social Psychology, 59, 475.

Pew Research Center. (2020). “Amid protests, majorities across racial and ethnic groups express support for the black lives matter movement.” June 12, 2020. Retrieved from https://www.pewsocialtrends.org/2020/06/12/amid-protests-majorities-across-racial-andethnic-groups-express-support-for-the-black-lives-matter-movement/

Pizarro, D., Uhlmann, E., \& Salovey, P. (2003). Asymmetry in judgments of moral blame and praise: The role of perceived metadesires. Psychological Science, 14, 267-272.

Powers, M., Faden, R. R., \& Faden, R. R. (2006). Social justice: The moral foundations of public health and health policy. Oxford University Press, USA.

Prentice, D. A., \& Miller, D. T. (1992). When small effects are impressive. Psychological Bulletin, 112, 160-164.

Pronin, E. (2008). How we see ourselves and how we see others. Science, 320, 1177-1180.

Rhodes, M., \& Chalik, L. (2013). Social categories as markers of intrinsic interpersonal obligations. Psychological science, 24, 999-1006.

Richeson, J. A., \& Nussbaum, R. J. (2004). The impact of multiculturalism versus colorblindness on racial bias. Journal of Experimental Social Psychology, 40, 417-423.

Roberts, S.O., Bareket-Shavit, C., Dollins, F.A., Goldie, P.D., Mortenson, E. (2020). Racial inequality in psychology. Perspectives in Psychological Science, Online First.

Roberts, S. O., Gelman, S. A., \& Ho, A. K. (2017). So it is, so it shall be: Group regularities license children's moral judgments. Cognitive Science, 41, 576-600. 
Roberts, S. O., Guo, C., Ho, A. K., \& Gelman, S. A. (2018). Children's descriptive-to-moral tendency replicates (and varies) cross-culturally: Evidence from China. Journal of Experimental Child Psychology, 165, 148-160.

Roberts, S. O., Ho, A. K., \& Gelman, S. A. (2017). Group presence, category labels, and generic statements influence children to treat descriptive group regularities as moral. Journal of Experimental Child Psychology, 158, 19-31.

Roberts, S. O., Ho, A. K., \& Gelman, S. A. (2019). The role of group norms in evaluating uncommon and negative behaviors. Journal of Experimental Psychology: General, 148(2), 374.

Roos, P., Gelfand, M., Nau, D., \& Lun, J. (2015). Societal threat and cultural variation in the strength of social norms: An evolutionary basis. Organizational Behavior and Human Decision Processes, 129, 14-23.

Rouse, S. V. (2015). A reliability analysis of Mechanical Turk data. Computers in Human Behavior, 43, 304-307.

Schwartz, S. H. (2007). Universalism values and the inclusiveness of our moral universe. Journal of Cross-cultural Psychology, 38, 711-728.

Schwartz, S. H., \& Bardi, A. (2001). Value hierarchies across cultures: Taking a similarities perspective. Journal of Cross-cultural Psychology, 32, 268-290.

Smetana, J. (2006). Social-cognitive domain theory: Consistencies and variations in children's moral and social judgments. In: M. Killen \& J. Smetana (Eds.) Handbook of Moral Development (pp. 119-153). Mahwah, NJ: Erlbaum. 
Smith, J. R., \& Louis, W. R. (2008). Do as we say and as we do: The interplay of descriptive and injunctive group norms in the attitude-behaviour relationship. British Journal of Social Psychology, 47, 647-666.

Suh, E., Diener, E., Oishi, S., \& Triandis, H. C. (1998). The shifting basis of life satisfaction judgments across cultures: Emotions versus norms. Journal of personality and Social Psychology, 74, 482.

Tajfel, H., Turner, J. C., Austin, W. G., \& Worchel, S. (1979). An integrative theory of intergroup conflict. In: W. Austin \& S. Worchel (Eds) The Social Psychology of Intergroup Relations (pp. 33-47). Monterey, CA: Brooks/Cole Publishing Co.

Turiel, E. (1978). Social regulations and domains of social concepts. New Directions for Child and Adolescent Development, 1, 45-74.

Tworek, C. M., \& Cimpian, A. (2016). Why do people tend to infer "ought" from "is"? The role of biases in explanation. Psychological Science, 27, 1109-1122.

U.S. Department of Health and Human Services. (2016). Health, united states, 2016: With chartbook on long-term trends in health (Report No. 76-641496). Hyattsville, MD: U.S. Centers for Disease Control and Prevention.

Williams, D. R., \& Collins, C. (2001). Racial residential segregation: a fundamental cause of racial disparities in health. Public Health Reports, 116, 404-416. 